\title{
Local Tsunamis and Distributed Slip at the Source
}

\author{
ERIC L. Geist ${ }^{1}$ and Renata Dmowska ${ }^{2}$
}

\begin{abstract}
Variations in the local tsunami wave field are examined in relation to heterogeneous slip distributions that are characteristic of many shallow subduction zone earthquakes. Assumptions inherent in calculating the coseismic vertical displacement field that defines the initial condition for tsunami propagation are examined. By comparing the seafloor displacement from uniform slip to that from an ideal static crack, we demonstrate that dip-directed slip variations significantly affect the initial cross-sectional wave profile. Because of the hydrodynamic stability of tsunami wave forms, these effects directly impact estimates of maximum runup from the local tsunami. In most cases, an assumption of uniform slip in the dip direction significantly underestimates the maximum amplitude and leading wave steepness of the local tsunami. Whereas dip-directed slip variations affect the initial wave profile, strike-directed slip variations result in wavefront-parallel changes in amplitude that are largely preserved during propagation from the source region toward shore, owing to the effects of refraction. Tests of discretizing slip distributions indicate that small fault surface elements of dimensions similar to the source depth can acceptably approximate the vertical displacement field in comparison to continuous slip distributions. Crack models for tsunamis generated by shallow subduction zone earthquakes indicate that a rupture intersecting the free surface results in approximately twice the average slip. Therefore, the observation of higher slip associated with tsunami earthquakes relative to typical subduction zone earthquakes of the same magnitude suggests that tsunami earthquakes involve rupture of the seafloor, whereas rupture of deeper subduction zone earthquakes may be imbedded and not reach the seafloor.
\end{abstract}

Key words: Tsunami, coseismic displacement, source parameters, nonuniform slip, crack, tsunami runup

\section{Introduction}

In recent years, there have been a number of subduction zone earthquakes that have generated unexpectedly large local tsunamis. For example, the maximum runup from the $1992 M_{w}=7.7$ Nicaragua earthquake was $9.1 \mathrm{~m}$ (BAPTISTA et al., 1993 ) and for the $1994 M_{w}=7.6$ Java earthquake, a maximum runup of $13.9 \mathrm{~m}$ was recorded (Tsus et al., 1995). The focus in this study is on shallow subduction zone thrust earthquakes, such as the aforementioned events, that generate most of the significant tsunamis. A critical assumption in calculating the static seafloor defor-

\footnotetext{
${ }^{1}$ U.S. Geological Survey, 345 Middlefield Rd., MS 999, Menlo Park, CA 94025, U.S.A.

${ }^{2}$ Division of Engineering and Applied Sciences and Department of Earth and Planetary Sciences, Harvard University, 29 Oxford St, Cambridge, MA 02138, U.S.A.
} 
mation and the tsunami derived from a particular earthquake is how slip is distributed throughout the rupture area. Results from seismic inversions indicate that interplate thrust earthquakes rupture heterogeneously both in space and time (as summarized by THATCHER, 1990). In contrast, however, many tsunami models assume that slip is distributed uniformly over the entire rupture area or over several large subevents. The objective of this study is to determine how these assumptions affect estimates of the local tsunami wave field and at what minimum dimension it is necessary to spatially discretize a heterogeneous rupture.

The physical processes that govern tsunami generation (elastic dislocation) and propagation (shallow water wave theory) are linked at the seafloor. For sufficiently large spatial wavelengths, the initial tsunami waveform mimics the vertical component of static displacement of the seafloor. Therefore, examination of the relationship between static source parameters and the local tsunami is centered on determining the static elastic displacement field from a given slip distribution. The hydrodynamics of propagation and runup are then taken into account to determine how heterogeneous rupture of subduction zone earthquakes affects the tsunami wave field away from the source region.

We introduce an alternative to the kinematic description of static deformation associated with earthquakes, commonly used in tsunami modeling. Rather than explicitly specifying slip, slip distributions are derived from a crack model (DMOWSKA and Kostrov, 1973; RUdNICKI and WU, 1995) by specifying the stress drop associated with the earthquake. Although crack models have commonly been used in understanding the dynamics of earthquake rupture (e.g., DAS, 1981), they have been curiously absent in tsunami studies. Crack models give important insight on the effect assumptions of the earthquake source process have on surface displacement, and hence the initial tsunami. Discretizing the continuous slip distributions derived from crack models allows us to determine the minimum spatial resolution needed to reconstruct the initial tsunami wave field. Using the 1992 Nicaragua tsunami earthquake as an example, we demonstrate that heterogeneous slip distributions derived from inversions of seismic waveform data provide information of sufficient spatial resolution to accurately model the local tsunami wave field. Details of how seismic inversions are correctly formulated, however, are not discussed here (see, for example, DAs and SuHADOLC, 1996).

\section{Static Displacement Field from Finite and Continuously Distributed Dislocations}

We first examine the static displacement field associated with finite dislocations. First, consider a Volterra dislocation in which slip $\delta$ (defined as $\delta=\left[\delta^{+}-\delta^{-}\right]$) is uniform across $\Sigma$ (Fig. 1a). Several authors have derived analytic expressions for the surface displacement overlying an inclined fault within a homogeneous halfspace that are particularly relevant in determining the initial conditions of tsunami 
propagation (SAVAGE and HASTIE, 1966; OKADA, 1985; among others). Care must be taken when using Volterra dislocations to calculate the vertical displacements for very shallow ruptures. For small values of $a$ (Fig. 1b), there is a strong short-wavelength component above the updip edge that is increasingly prevalent with decreasing $\alpha$ (see Appendix).

Next, consider a Somigliana dislocation $\delta(\xi)$ along an inclined planar fault in two dimensions (Fig. 1b). The displacement associated with a single edge disloca-
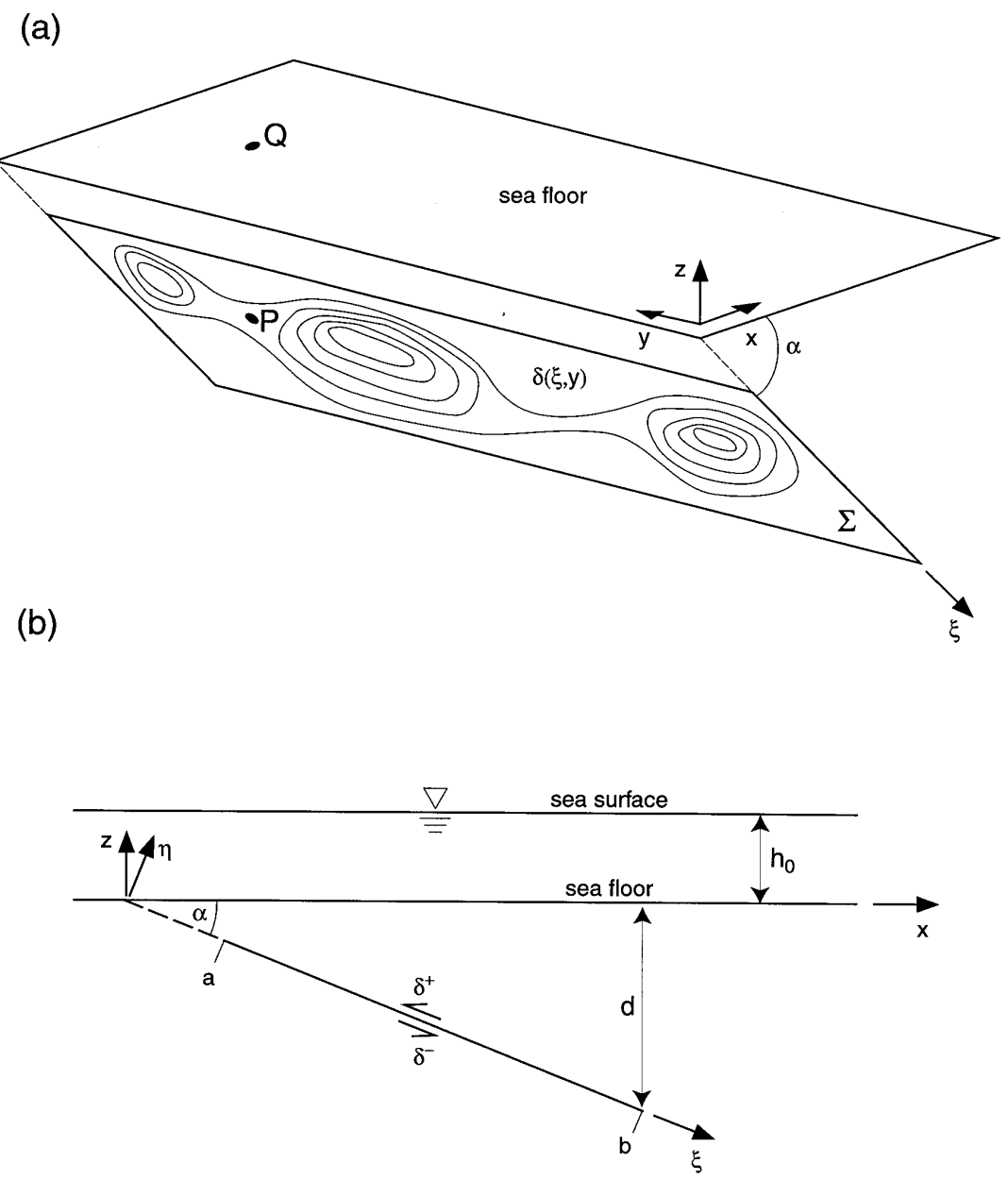

Figure 1

Geometry of dip-slip faulting, typical of interplate subduction zone earthquakes. (a) Three-dimensional view of the fault plane for which slip varies in both the dip $(\xi)$ and strike $(y)$ directions. The magnitude of slip is schematically indicated by the contours. For this study, only pure dip-slip is considered. (b) Cross-sectional view of a rupture zone defined by $a \leq \xi \leq b$ where the $\xi$ axis is aligned with the dip direction of the fault plane. Variable slip along the $\xi$ axis is defined as $\delta(\xi) \equiv\left[\delta^{+}-\delta^{-}\right]$. 
tion at $\xi=s$ of strength $\beta$ in a half-space along the fault derived by FreUnD and BARNETT (1976), using a complex-variable representation of stresses, is (including the correction noted by RUDNICKI and WU, 1995):

$$
u_{z}(x, s)=\beta U_{z}(x, s)
$$

where

$$
U_{z}(x, s)=\frac{x s \sin ^{2} \alpha}{\pi\left(x^{2}+s^{2}-2 x s \cos \alpha\right)}+\frac{\sin \alpha}{\pi} \tan ^{-1}\left(\frac{x-s \cos \alpha}{s \sin \alpha}\right) .
$$

Recently, Savage (1998) also derived the displacement field for an edge dislocation in a layered half-space. Any arbitrary distribution of slip along an inclined fault can be posed in terms of a dislocation density

$$
\delta_{\xi}^{\prime}(\xi)=\beta D_{\xi}(\xi)
$$

where $D_{\xi}(\xi)$ is the edge dislocation density along the $\xi$-axis coincident with the fault plane and $b$ is the magnitude of the Burgers vector in the $\xi$ direction of the infinitesimal dislocation between $\xi=s$ and $\xi=s+d s$ (WeERTMAn, 1964). The vertical displacement arising from arbitrary slip is then obtained from the superposition of infinitesimal edge dislocations using (1) (FREUND and BARNETT, 1976):

$$
u_{z}(x, 0)=\int_{a}^{b} U_{z}(x, s) \delta_{\xi}^{\prime}(s) d s
$$

where $a$ and $b$ represent the undip and downdip distances along the $\xi$ axis as shown in Figure $1 \mathrm{~b}$. Thus, for continuously distributed edge dislocations, the displacement field is dependent on the slip gradient $\delta_{\xi}^{\prime}(\xi)$ along $a \leq \xi \leq b$ rather than strictly the slip distribution itself.

\section{Theoretical Slip Distributions}

The effect of using assumed uniform (Volterra) dislocations for tsunami propagation models is examined by comparing the associated initial tsunami waveform to a scalar moment-equivalent tsunami waveform derived from a static crack model. For this section and the next, elastic deformation and tsunami dynamics, respectively, are first considered in the $(x-z)$ plane, implying plane strain in the solid earth and layer-mean transport (one horizontal dimension, $x$ ) in the water column. Undoubtedly, along-strike variations in slip also have important effects on tsunami generation (as shown in Section 5), however in this section we are concerned with how downdip changes in slip distribution affect the profile of the initial waveform that, in turn, controls the dynamics of local runup (TADEPALLi and SynOlakis, 1996). 


\subsection{Slip Distributions Derived from Crack Models}

Much work has recently been done in establishing the theoretical slip distributions and surface deformation for cracks of different configurations (e.g., Kostrov and DAs, 1984; MCTigue and Segall, 1988; Wu et al., 1991; RudNicki and WU, 1995). For a subduction zone thrust fault, an expanding rupture front can be simply envisioned as a mode II fracture in the $x-z$ plane at time scales consistent with the rise time of the event. We briefly review the mechanics of dip-slip faulting (mode II) for two cases as initially investigated by DMOwSKA and Kostrov (1973): (1) imbedded rupture and (2) rupture propagating to the surface.

We start with an imbedded rupture, initially neglecting friction, as shown in Figure 1b. As indicated in the previous section and by DMOWSKA and Kostrov (1973), an arbitrary Somigliana dislocation along a crack of finite length can be considered as the linear superposition of edge dislocations along the length of the crack. The resulting integral equation for slip gradient is

$$
\frac{1}{\pi} \int_{a}^{b} \frac{\delta^{\prime}(s)}{s-\xi} d s+\frac{1}{\pi} \int_{a}^{b} K(\xi, s) \delta^{\prime}(s) d s=\frac{2(1-v)}{\mu} f(\xi)
$$

where $\lambda$ and $\mu$ are Lamé's constant, $v$ is Poisson's ratio, and $f(\xi)$ represents the shear stress resolved along the plane of the crack. In terms of principal stresses, $f(\xi)$ is given by:

$$
f(\xi) \equiv \sigma_{\xi \eta}^{0}=\frac{1}{2}\left(\sigma_{x x}^{0}-\sigma_{z z}^{0}\right) \sin 2 \alpha+\sigma_{x z}^{0} \cos 2 \alpha
$$

(zero superscript indicating initial stress). The kernel $K(\xi, s)$ is given in DMOwsKA and Kostrov (1973). The integral Equation (4) includes inverse square-root singularities at the crack tips. The strength of these singularities is given by the mode-II stress intensity factor defined by (RICE, 1968; RUDNICKI and WU, 1995)

$$
K_{\mathrm{II}}=\lim _{\xi \rightarrow a, b} \frac{\mu}{2(1-v)} \sqrt{2 \pi \xi} \delta^{\prime}(\xi) .
$$

The distribution of slip can be determined by reduction of the singular integral Equation (4) to simultaneous linear equations using a Chebyshev polynomial technique described by ERdogan and Gupta (1972) and DMOwsKa and Kostrov (1973).

A Coulomb friction condition is introduced such that slip occurs when (following the notation of RUDNICKI and WU, 1995):

$$
\left|\sigma_{\xi \eta}\right|=k \sigma_{\eta \eta}
$$

where $k$ is the coefficient of friction. In the formulation of DMOwSKA and Kostrov (1973) and RUDNICKI and WU (1995), $k$ is constant and thus does not incorporate rate- and state-dependent sliding friction used in dynamic models of rupture (DieTERICH, 1979). As indicated by DMOwsKa and Kostrov (1973), the 
integral Equation (4) can be modified to account for Coulomb friction by adjusting the kernel $K(\xi, s)$ and the right-hand side of (4) accordingly:

$$
f_{k}(\xi)=f(\xi)-k \sigma_{\eta \eta}^{0}
$$

$\left(f_{k}(\xi)\right.$ replaces $f(\xi)$ in (4)). The integral equation is solved using the numerical method of ERDOGAN and GUPTA (1972) as before, resulting in the slip distribution shown in Figure 2a. For deeply imbedded cracks, dislocation does not affect the normal stress along the fault and therefore, an analytical expression for the distribution of slip can be derived (RUDNICKI and WU, 1995).

As noted by DMOwSKA and RICE (1986), for faults near or rupturing the surface involving the Coulomb friction condition (7), any perturbations in the shear stress caused by slip will also affect the normal stress along the fault. This introduces nonlinearity into the integral equations and iterative solutions must be invoked (RUDNICKI and WU, 1995). The resulting slip distribution becomes increasingly skewed updip as $a \rightarrow 0$. RUDNICKI and WU (1995) demonstrate that the updip propagation of slip is unstable when the length of the slip zone exceeds a critical width ( $\left.W_{\text {crit }}\right)$. Small values of the ratio of $d / W=a \sin \alpha /(b-a)$ become increasingly unstable, such that for small values of $W_{\text {crit }}$, shallow earthquakes are likely to result in surface rupture.

For the case of surface rupture, the appropriate condition at the updip rupture edge is (DMOWsKa and Kostrov, 1973)

$$
\delta^{\prime}(\xi), K_{\mathrm{II}}(\xi)=0 \text { for } \xi=0 .
$$

The shape of the slip distribution for surface rupture (Fig. 3a) is dramatically different than for even a shallow imbedded rupture, owing to the fact that shear stress along the crack plane is required to vanish at the free surface. The slip distribution for surface rupture is a quarter-ellipse shape, with the maximum slip twice that for an imbedded rupture with the same stress drop (KNOPOFF, 1958; Boore and Dunbar, 1977; Shimazaki, 1986). As noted by Shimazaki (1986), there appears to exist a discrete threshold between small imbedded earthquakes and large surface rupture earthquakes in which the scalar seismic moment ideally increases abruptly by a factor of two, owing to the different boundary conditions associated with surface rupture. The exact shape of the slip distribution shown in both Figures $2 \mathrm{a}$ and $3 \mathrm{a}$ depends on the assumed stress-drop magnitude and distribution, which itself is commonly heterogeneous.

The vertical displacement of the seafloor $u_{z}(x)$ is calculated using Equations (1) and (3). Conventional numerical integration techniques are used to evaluate Equation (3) at a fine discretization level equal to that used in calculating slip distribution by the Chebyshev polynomial technique (i.e., $n=100$ ) (Fig. 2b, long-dashed line). Alternatively, to include the effect of the slip-gradient singularities at the crack tips, the same Chebyshev polynomial technique could be used to evaluate the vertical displacement integral (Fig. 2b, short-dashed line). These singularities can be 
(a)

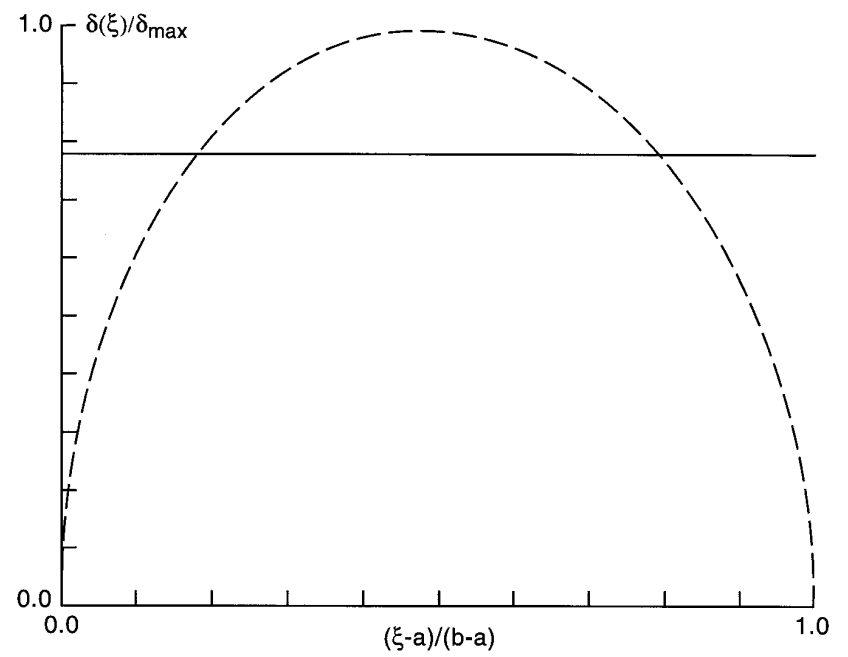

(b)

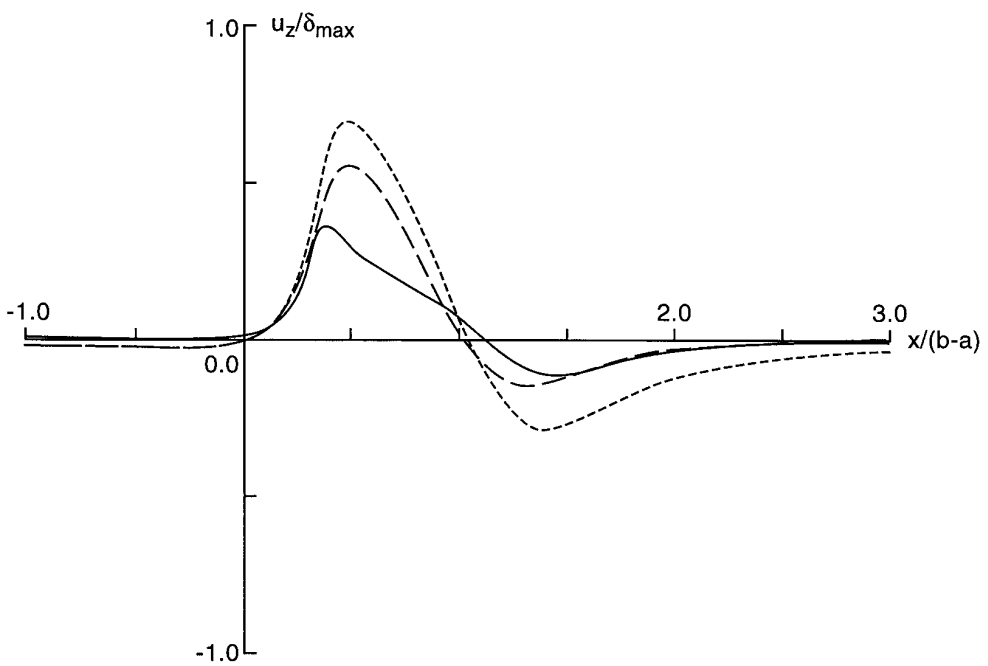

Figure 2

Slip distribution (a) and vertical seafloor displacement profile (b) for an imbedded crack $(a / W=0.36$, dashed line) where the average stress drop is $9.0 \mathrm{MPa}$ along a fault that dips $\alpha=20^{\circ}$. Vertical axes for (a) and (b) are normalized with respect to the maximum slip. Horizontal axes normalized with respect to the fault width. Solid line indicates average slip in (a) and associated vertical displacement profile in (b). Short dashed line in (b) represents vertical displacement profile that includes the contribution of the crack-tip singularity points to the deformation field.

thought of, using the description of BILBY and Eshelby (1969), as dislocations "piled up" at the crack tips. Stress singularities at the crack tips, however, are physically manifested by inelastic small-scale yielding near the crack tips (RICE, 
1968; DMOWSKA and Rice, 1986) and therefore possibly yield fictitious components of deformation under a purely elastic description. RICE (1968) indicates that although the stress-intensity factors of the crack-tip singularities can conveniently characterize the applied load at the crack tip (and crack-growth energy release $G$ ), the singularity points are not necessarily linked to the actual response of the

(a)

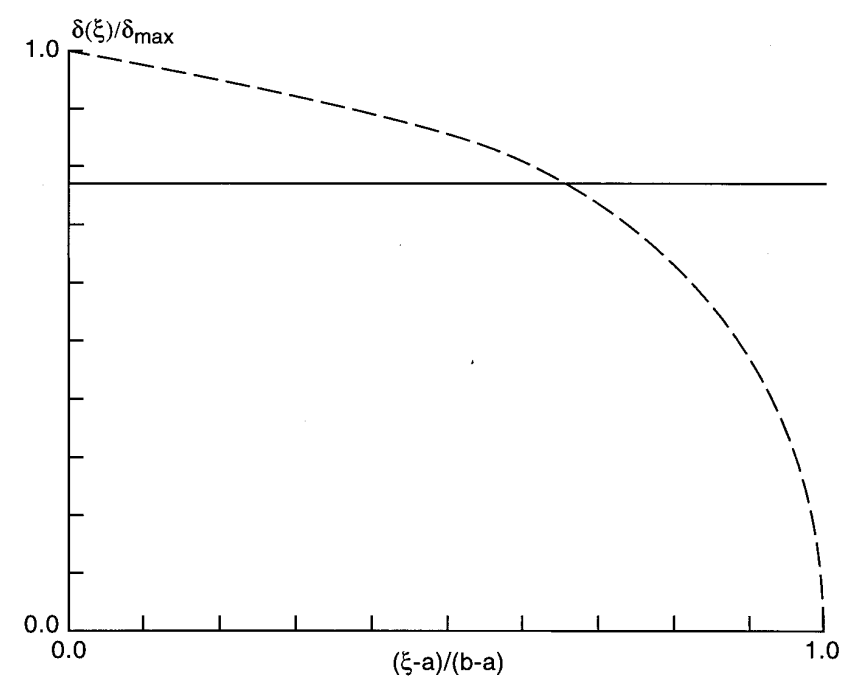

(b)

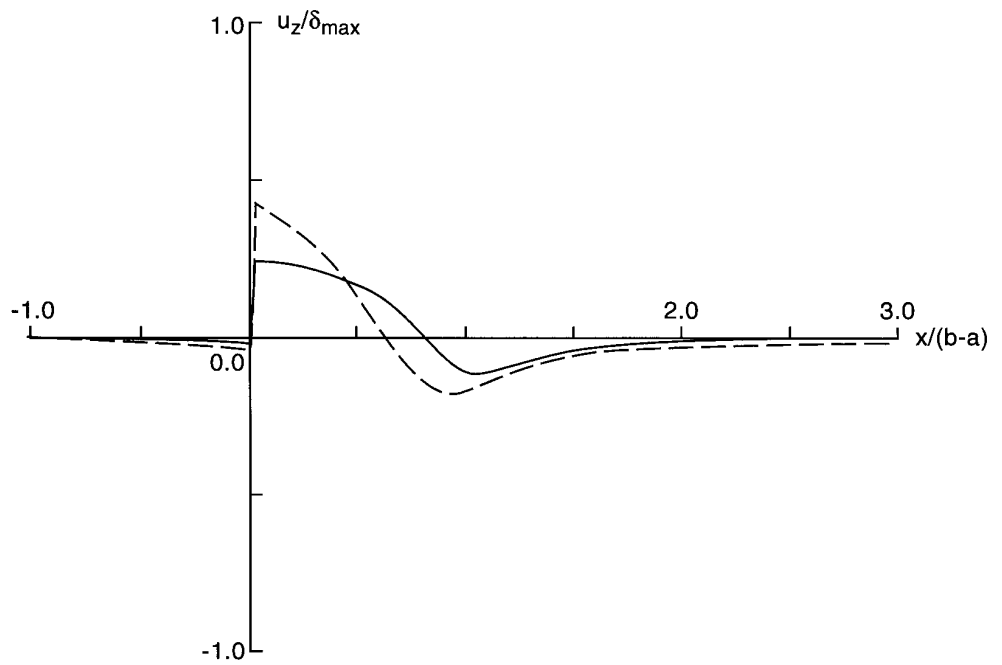

Figure 3

Slip distribution (a) and vertical seafloor displacement profile (b) for a surface-rupturing crack (dashed line) where the average stress drop is $4.8 \mathrm{MPa}$ along a fault that dips $\alpha=20^{\circ}$. Solid line indicates average slip in (a) and associated vertical displacement profile in (b). 


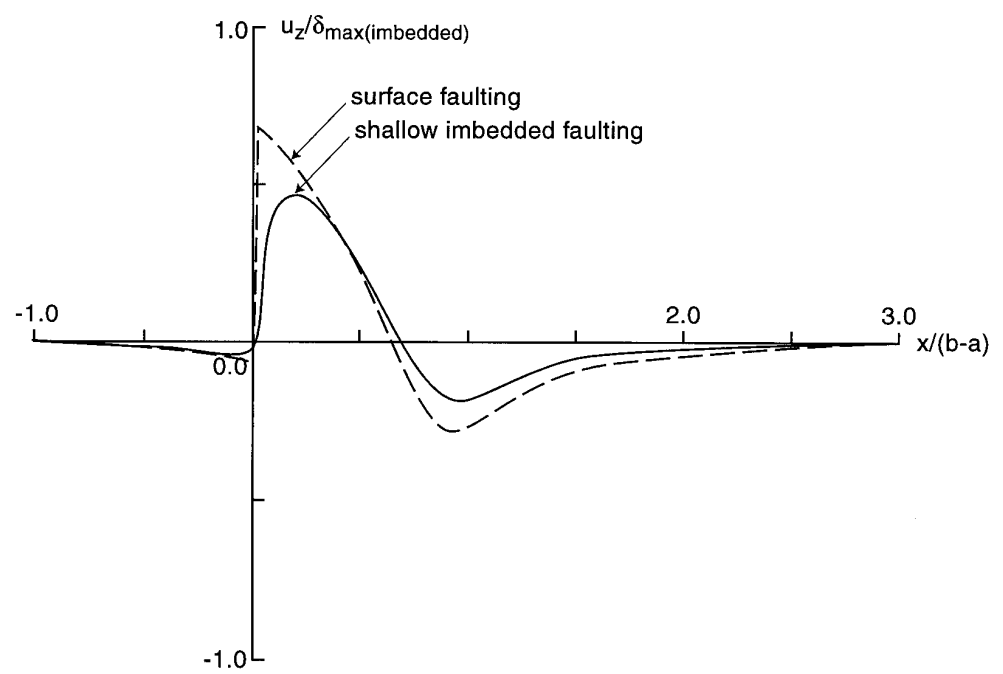

Figure 4

Comparison of vertical displacement profiles associated with a shallow imbedded crack $(a / W=0.036$, solid line) and surface-rupturing crack (dashed line) along a fault that dips $\alpha=20^{\circ}$. Average stress drop for the shallow imbedded crack and surface-rupturing crack is $6.3 \mathrm{MPa}$ and $4.8 \mathrm{MPa}$, respectively.

material surrounding the crack (a similar explanation is given by IDA, 1973). For this reason, conventional numerical integration techniques are used to calculate the static, vertical displacement profile.

In comparison to the elliptical slip distributions from an imbedded crack, uniform slip results in a lower maximum vertical displacement and concentrated deformation near the edges of the rupture zone, resulting in sharper extrema at the surface locations directly above the crack tips $(a$ and $b$ ) (Fig. 2b). Similarly, the maximum vertical displacement associated with the slip distribution from a surfacerupturing crack is greater than that associated with a uniform slip dislocation equal in magnitude to the average of the slip distribution (Fig. 3b). In addition, an increase in maximum vertical displacement is observed for a surface-rupturing crack in comparison to that for a very shallow imbedded crack $(a / W=0.036$, Fig. 4).

\subsection{Prescribed Slip Distributions with a Smooth Closure Condition}

Other theoretical slip distributions have been formulated so that stress concentrations at the crack tips are finite (termed a smooth closure condition by BILBY and ESHELBY, 1969). We specifically examine prescribed slip distributions, although other techniques such as regularization have been implemented in the framework of boundary integral equations (FUKUYAMA and MADARIAGA, 1995; TADA and 
YAMASHITA, 1997). FREUND and BARNETT (1976) use the following prescribed slip distribution:

$$
\delta^{\prime}=\Delta \begin{cases}\frac{12}{q^{3}}\left(q \gamma-\gamma^{2}\right), & \gamma<q \\ \frac{12}{(1-q)^{3}}\left(\gamma^{2}-\gamma(1+q)+q\right), & \gamma>q\end{cases}
$$

where $\Delta$ is a scaling coefficient, $\gamma \equiv(\xi-a) /(b-a)$, and $q(0<q<1)$ controls the skewness of the slip distribution. The particular form (10) is invoked so that $K_{\mathrm{II}}(a)=0$ and $K_{\mathrm{II}}(b)=0$ (i.e., $\delta^{\prime}(a)=0$ and $\delta^{\prime}(b)=0$ Equation (6)). The stress drop across the length of the crack is finite but variable. In the context of analyzing the mechanics of both single-slip events (earthquakes) and the cumulative slip along a fault, CowIE and SCHOLZ (1992) and BürGMANN et al. (1994) relate the tapering of slip distributions near the crack tips to inelastic deformation. For crack models in which the stress concentration near the crack tip is limited by the yield stress of the surrounding material, the amount of taper is related to the size of the frictional breakdown zone near the crack tip (CowIE and SHipton, 1998).

A comparison of the vertical displacement profiles associated with the smooth closure distribution of FREUND and BARNETT (1976) where $q=0.3$ and uniform slip is shown in Figure 5. Like the slip distribution from the purely elastic crack, the maximum vertical displacement for the smooth-closure slip distribution is greater than that for uniform slip. The difference, however, is not as great for the smooth-closure model, because the integrated slip gradient is not as large for the smooth-closure model in comparison to the elastic crack model. Because slip is concentrated toward the center of the rupture for either the elastic crack or smooth-closure model, the maximum initial amplitude and leading-wave steepness is greater than for the tsunami calculated under the assumption of uniform slip (Figs. 2b and 5b, long-dashed line).

\subsection{Effect of Descretizing Slip Distributions}

In this section we examine at what level continuous slip distributions can be discretized to provide an adequate approximation to the vertical displacement profile. The displacement profile associated with a discretized slip distribution is calculated by the linear superposition of the displacement field from individual Volterra dislocations along a dipping fault using the method of SAVAGE and HASTIE (1966). Coarse discretization $(n=4)$ of the slip distribution derived from the smooth closure condition (Equation (12)) can acceptably reproduce the vertical displacement profile (Fig. 6). In most tsunami applications, therefore, a few subevents with uniform slip in the dip direction can adequately approximate the vertical displacement profile in comparison to using continuous slip distributions. 
Assuming uniform slip for the entire dip dimension of the rupture zone $(n=1)$, however, is prone to yielding inaccurate results (Fig. 6).

(a)

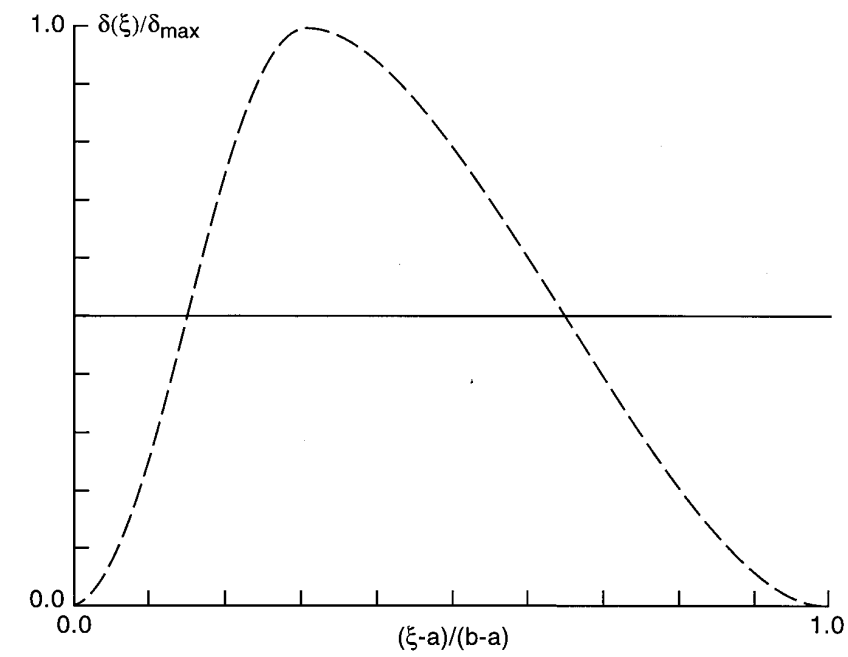

(b)

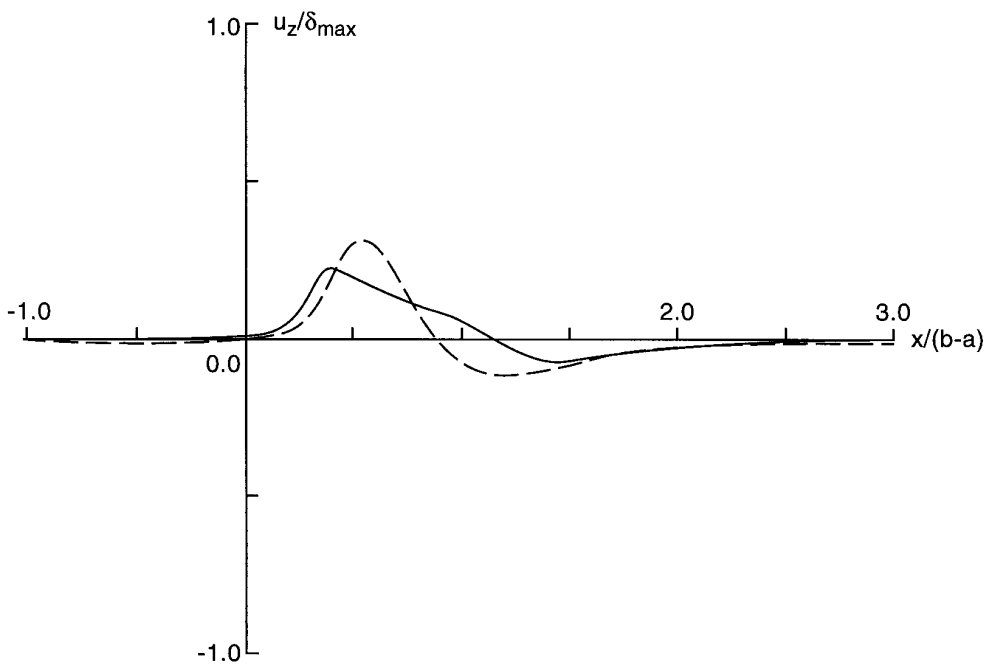

Figure 5

Slip distribution (a) and vertical seafloor displacement profile (b) for an imbedded rupture (dashed line) along a fault that dips $\alpha=20^{\circ}$. The prescribed slip distribution of FREUND and BARNETT (1976) (Equation (10)) is shown for $q=0.3$. Using Equation (10), the maximum slip is twice the average slip. Solid line indicates average slip in (a) and associated vertical displacement profile in (b) 
(a)

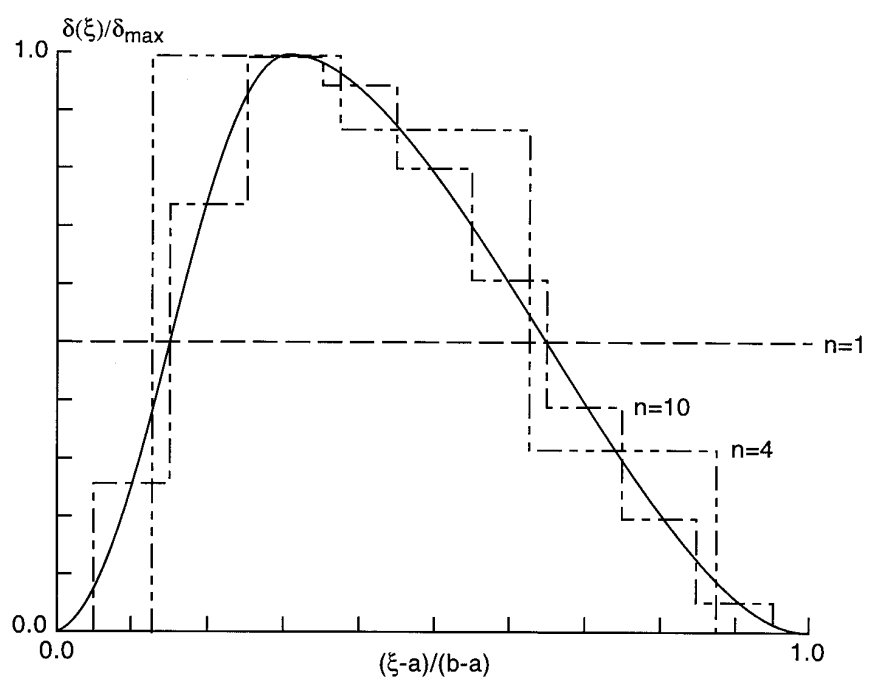

(b)

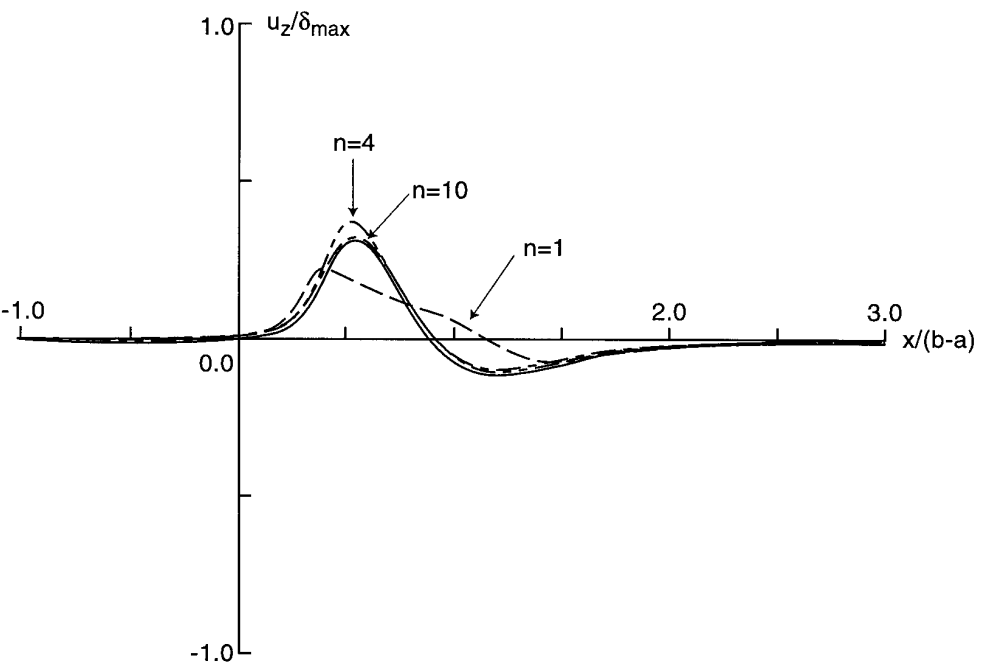

Figure 6

Discretized slip distributions (a) and vertical seafloor displacement profiles (b) along a fault that dips $\alpha=20^{\circ}$ in comparison to the continuous prescribed slip distribution of FreUND and BARNETT (1976) shown in Figure 4.

\section{Effect on Local Propagation and Runup}

Tsunamis are gravity waves excited by the sudden increase in potential energy that arises from vertical displacement of the seafloor during earthquake rupture. As 
such, the magnitude and pattern of vertical seafloor displacement $\left(u_{z}(x, y, t)\right)$ dictates the amplitude and waveform $(\eta(x, y, t))$ of the ensuing tsunami. In general, for the rise times of most earthquakes, displacement of the seafloor can be considered instantaneous relative to the propagation speed of tsunamis such that the initial tsunami wave field mimics the vertical seafloor displacement field. In certain cases, other factors must be accounted for, such as the horizontal component of displacement in regions of steep bathymetry (TANIOKA and SATAKE, 1996). Also, wavelength components of the vertical displacement field less than approximately three times the water depth are attenuated through the water column during tsunami generation. Attenuation of short-wavelength components of the vertical displacement profile are mostly a concern in the cases of shallow and surface faulting. Starting with the three-dimensional Green's function for water motion in an ocean of finite depth (STOKER, 1957), KAJIURA (1963) demonstrates that the effect of attenuation on the initial tsunami wave field can be approximated by essentially applying a $1 / \cosh (k h)$ filter to the vertical displacement field, where $k$ is the wave number, $h$ is the water depth (see also, KAJIURA, 1981).

Because of the long wavelengths of tsunamis in the open ocean, tsunami propagation is modeled using the shallow-water wave equations:

$$
\begin{array}{ll}
\frac{\partial(\eta+h)}{\partial t}+\nabla \cdot[\mathbf{v}(\eta+h)]=0 & \text { Continuity Equation } \\
\frac{\partial \mathbf{v}}{\partial t}+(\mathbf{v} \cdot \nabla) \mathbf{v}+g \nabla \eta=0 & \text { Momentum Equation }
\end{array}
$$

where $\mathbf{v}=v_{i}(i=1,2)$ are the depth-averaged components of horizontal velocity, $\eta$ and $h$ are the water surface elevation and water depth, respectively, relative to a reference state, and $g$ is the gravitational acceleration. Several phenomena characteristic of tsunami propagation described by shallow-water wave theory include the following: (1) after the tsunami leaves the source region, the amplitude of the initial wave field is reduced by approximately half for a rupture of sufficient length; (2) as the tsunami shoals during propagation from the source region toward shore, the tsunami is amplified according to Green's law:

$$
\frac{\eta_{1}}{\eta_{0}} \sim\left(\frac{h_{1}}{h_{0}}\right)^{-1 / 4} ;
$$

and (3) the runup (and backwash) of tsunamis is controlled by the beach slope as well as the peak amplitude and leading wave steepness of the wave (ToGASHI, 1983; SYNOLAKIS, 1987). For the latter phenomenon, runup laws have recently been derived from shallow-water wave theory to relate the leading tsunami waveform to 
maximum runup height $(\mathbf{R})$. A family of waves termed $N$ waves by TADEPALLI and SyNOLAKIS $(1994,1996)$ closely represent most local tsunami waveforms (i.e., the profile of vertical surface displacement) generated by thrust fault events. The generalized, nondimensionalized $N$ wave given by TADEPALli and SynOlakis (1996) is

$$
\eta(x)=\left.(\varepsilon H)\left(x-X_{2}\right) \operatorname{sech}^{2}[\gamma(x-\theta)]\right|_{t=0}
$$

where $\varepsilon H$ is the wave amplitude ( $\varepsilon$, an arbitrary small constant), $\gamma_{s}=\sqrt{\frac{3}{4} p_{0} H}, \theta=$ $X_{1}+c t$, and $p_{0}$ is a steepness parameter. TAdePalli and SynOlaKIS (1996) have demonstrated that $N$ waves are hydrodynamically stable waveforms that do not fission (disintegrate into separate waves) over large distances. The maximum runup of $N$ waves across a beach slope of angle $\beta$ is (TADEPALLI and SynOlakis, 1996)

$$
\mathbf{R}=3.3 \varepsilon p_{0}^{1 / 4} Q(L, \gamma) \mathbf{R}_{\text {sol }}
$$

where $Q(L, \gamma)$ is a factor determined numerically and $\mathbf{R}_{\text {sol }}$ is the runup of a solitary wave with identical $H$ (SyNOLAKIs, 1987):

$$
\mathbf{R}_{\mathrm{sol}}=2.831 \sqrt{\cot \beta} H^{5 / 4} .
$$

Whereas, Green's law (11) is contained in the derived $N$-wave runup law (15), other parameters of the waveform besides maximum amplitude (namely, effective wavelength and amplitude ratio between leading phases) also significantly affect the maximum runup of local tsunamis. GEIST (1998) demonstrates that maximum runup is approximately linearly proportional to wave steepness (specified as $\tan ^{-1}$ $\left(H / X_{L}\right)$ where $X_{L}$ is the distance between the leading depression and trailing peak) except for very broad waves, though the relationship is also dependent on beach slope. TAdepalli and Synolakis (1996) also indicate that maximum runup is functionally dependent on the amplitude ratio between the leading depression and trailing peak. Therefore, differences in the entire initial tsunami waveform lead to considerable differences in runup estimates. In general, tsunamis generated from nonuniform slip distributions that have a greater maximum amplitude $(H)$ and greater leading wave steepness than tsunamis calculated assuming uniform slip (Figs. 2 and 3) result in significantly higher runup. Similarly, the greater initial tsunami amplitude (but similar leading wave steepness) that results from surface rupture in comparison to shallow-imbedded rupture (Fig. 4), corresponds to slightly higher tsunami runup for surface-rupture events.

\section{Local Tsunamis Computed from Two-dimensional Slip Distributions}

Results from the previous sections indicate that large slip gradients in the dip direction have an important effect on the initial tsunami waveform and local tsunami runup. The results also indicate that seafloor displacement can be closely 
approximated with discretized slip distributions in comparison to continuous slip distributions. In this section we extend our analysis to examine how two-dimensional slip distributions in the fault plane affect tsunami propagation in $(x, y, t)$ space.

Seismic inversions of large interplate thrust earthquakes have shown that slip can commonly vary by an order of magnitude, and thus cannot be simply characterized by a simple crack. This spatial variability in slip can, however, be envisioned as the result of dynamic interaction between individual cracks (DMOWSKA and RiCE, 1986). To explain the variability of slip, authors have formulated dynamic models involving the interaction of ruptures across barriers (DAS and AKI, 1977) and using rate- and state-dependent sliding friction (TSE and Rice, 1986; Stuart, 1988; Ben-Zion and Rice, 1995; Boatwright and Cocco, 1996; COCHARD and MADARIAGA, 1996). Because the dynamics of earthquake rupture have only a minor effect on the local tsunami, we do not pursue more sophisticated theoretical treatments involving dynamic friction, instead focusing our efforts on relating two-dimensional static slip distributions to the local tsunami wave field. Specifically, we examine the response of the local tsunami to prescribed and observed slip variations in the $\xi$ and $y$ directions (Fig. 1b).

\subsection{Numerical Methods}

Vertical surface displacement in $(x, y)$ space (specifically, the static elastic Green's functions) cannot be calculated for an arbitrary continuous distribution of slip except for simple rupture geometries and analytic slip functions (MA and KUSZNIR, 1992; SINGH et al., 1994). For arbitrary slip distributions, therefore, vertical displacement of the seafloor associated with slip distributed in $(\xi, y)$ space is calculated from a discretized approximation using the point-source expressions of OKADA (1985) for dip-slip faulting. It is worth noting that short-wavelength components of deformation are also apparent in the point-source expressions for very shallow source depths (Appendix). The total displacement field is calculated from the linear superposition of the displacement field from each of the surface elements (cf., SATAKE, 1993). A more geometrically versatile technique using triangular elements has recently been proposed by Wu et al. (1991) and JEYAKUMARAN et al. (1992).

For the purpose of examining the effect of distributed slip in two dimensions, a model is constructed in which slip is discretized to $10-\mathrm{km}$ square surface elements over a $70 \mathrm{~km} \times 270 \mathrm{~km}$ rupture zone (Fig. 7). The horizontal grid size for which seafloor displacement and tsunami propagation is calculated is $3.5 \mathrm{~km}$, and the time step for propagation is $10 \mathrm{~s}$. A simple two-piece linear-varying water depth is used for the left half of the grid to simulate local shoaling of the tsunami over a continental-type margin (Fig. 7). The initial tsunami wave field is calculated from the vertical displacement field using the $1 / \cosh (k h)$ filter noted by KAJIURA (1963, 
1981). Propagation of the tsunami is calculated using the two-dimensional, linearlong wave equation with a full reflection boundary condition along the shoreline $(h=0)$ and radiation boundary conditions (REID and BoDINE, 1968) along the open ocean boundaries.

\subsection{Results}

The effect of nonuniform slip in both the dip and strike direction on the local tsunami wave field is determined in comparison to uniform two-dimensional slip. Figure 8 shows the initial tsunami waveform using $1 \mathrm{~m}$ of uniform slip over the rupture area illustrated in Figure 7, along with synthetic marigrams of the local tsunami propagating toward the shoreline and of the outgoing tsunami propagating toward the open ocean. Note that the local tsunami is fully reflected at the shoreline, with the reflected phase superimposed on the later part of the direct arrival. Figure 9 shows the synthetic marigrams associated with slip variations in the dip $(\xi)$ direction calculated from Equation (10), where $q=0.3$ and the average slip is again $1 \mathrm{~m}$. In comparison to Figure 8, the amplitude of both the local and outgoing tsunamis is significantly greater for nonuniform slip in the dip direction, a confirmation in two dimensions of the results shown in Figure 5. The third test performed is the effect of slip variations in the strike $(y)$ direction on the local tsunami wave field (Fig. 10). For this case, slip remains constant in the $\operatorname{dip}(\xi)$

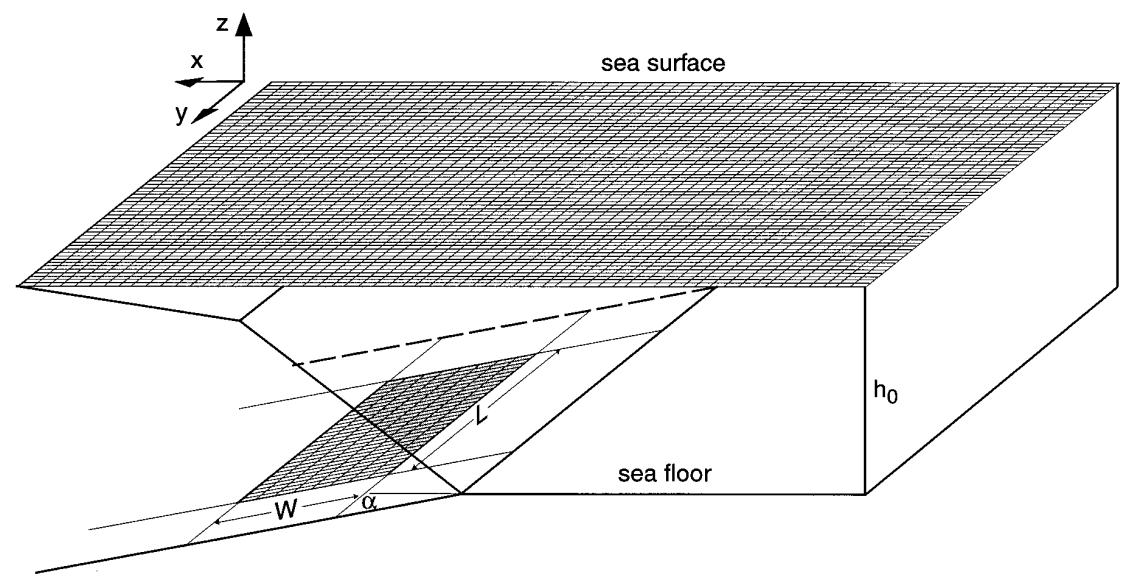

Figure 7

Model geometry for calculating the local tsunami wave field associated with slip variations in both the dip and strike directions (Figs. 8-10). Discrete representation of slip distribution shown by grid aligned with dipping fault plane $(10 \mathrm{~km}$ grid spacing, $L=270 \mathrm{~km}, W=70 \mathrm{~km})$. Static elastic displacement and tsunami propagation calculations performed on grid at the sea surface $(3.5-\mathrm{km}$ grid spacing). Subduction zone margin bathymetry simply represented by a two-piece linear slope for the left side (coast-trench distance $=110 \mathrm{~km}$ with a slope change at $55 \mathrm{~km})$ and constant water depth $\left(h_{0}=4 \mathrm{~km}\right)$ for the right side. 


\section{Source Depth: 10-38km}

Uniform Slip: $1 \mathrm{~m}$

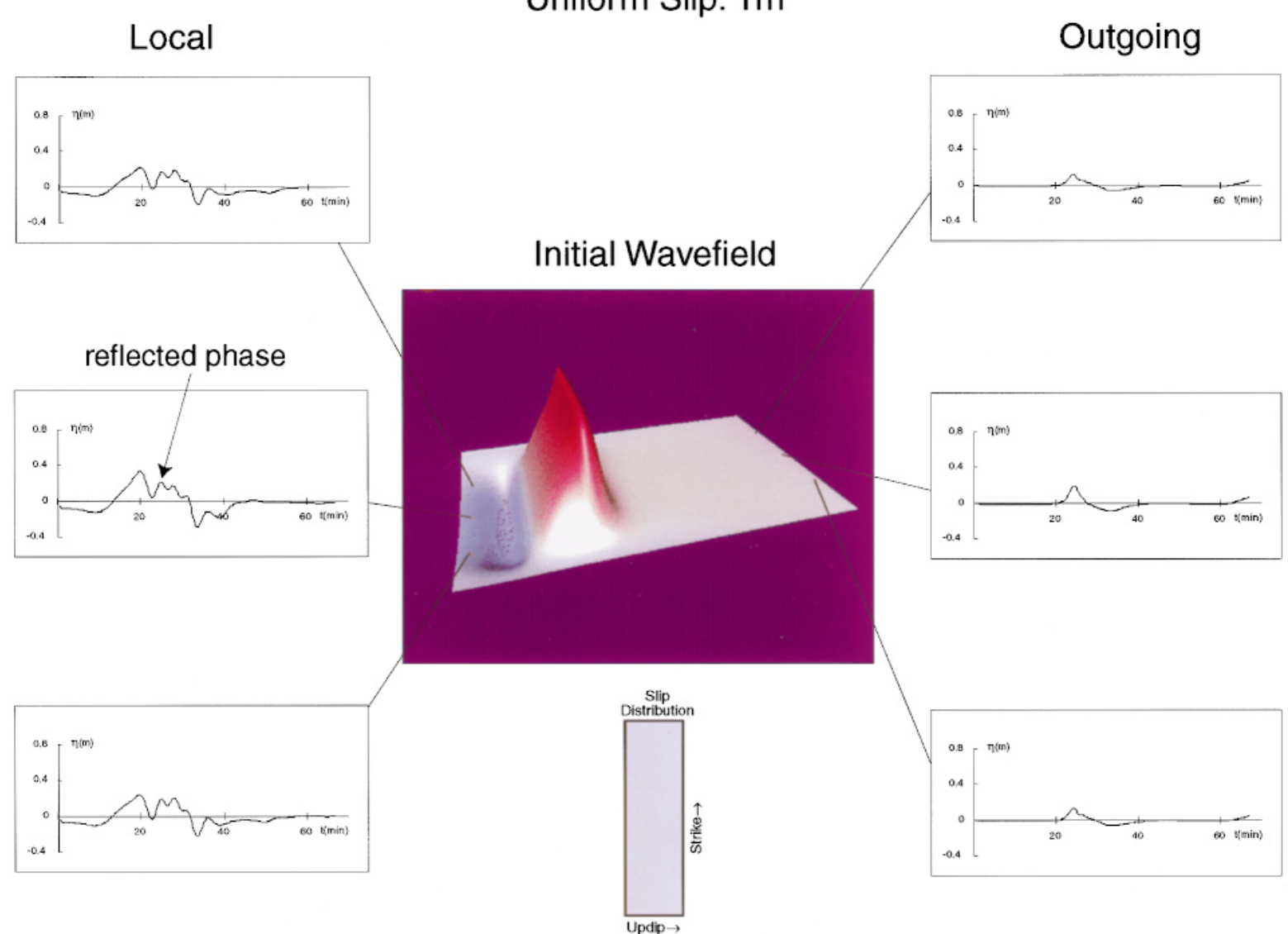


Source Depth: 10-38km

Dip Discretized

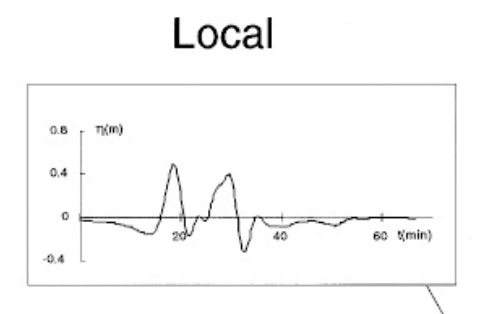

(distribution skewed updip)

Average Slip: $1 \mathrm{~m}$

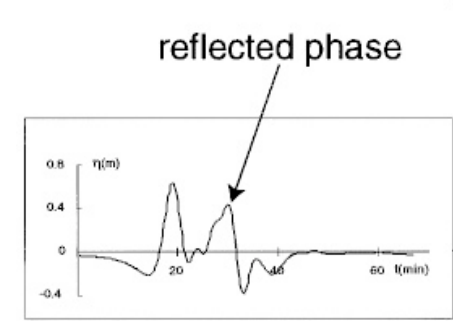

Initial Wavefield

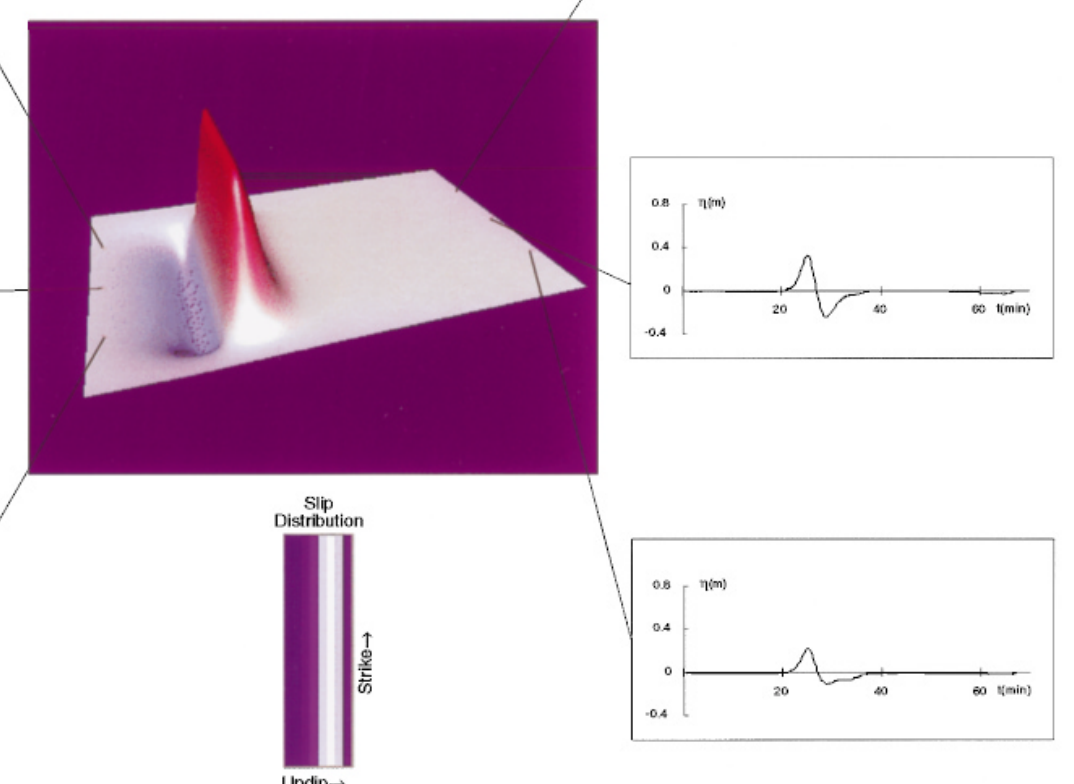

Initial tsunami waveform and synthetic marigrams for nonuniform slip in the dip direction. Slip is constant in the strike direction. Slip distribution calculated using Equation (10), such that the average slip is identical to the constant slip used in Figure $8(1 \mathrm{~m})$. For the slip distribution image, amplitude is normalized to the individual maximum value. Dark colors in the slip distribution represent low slip values and light colors represent high slip values. 


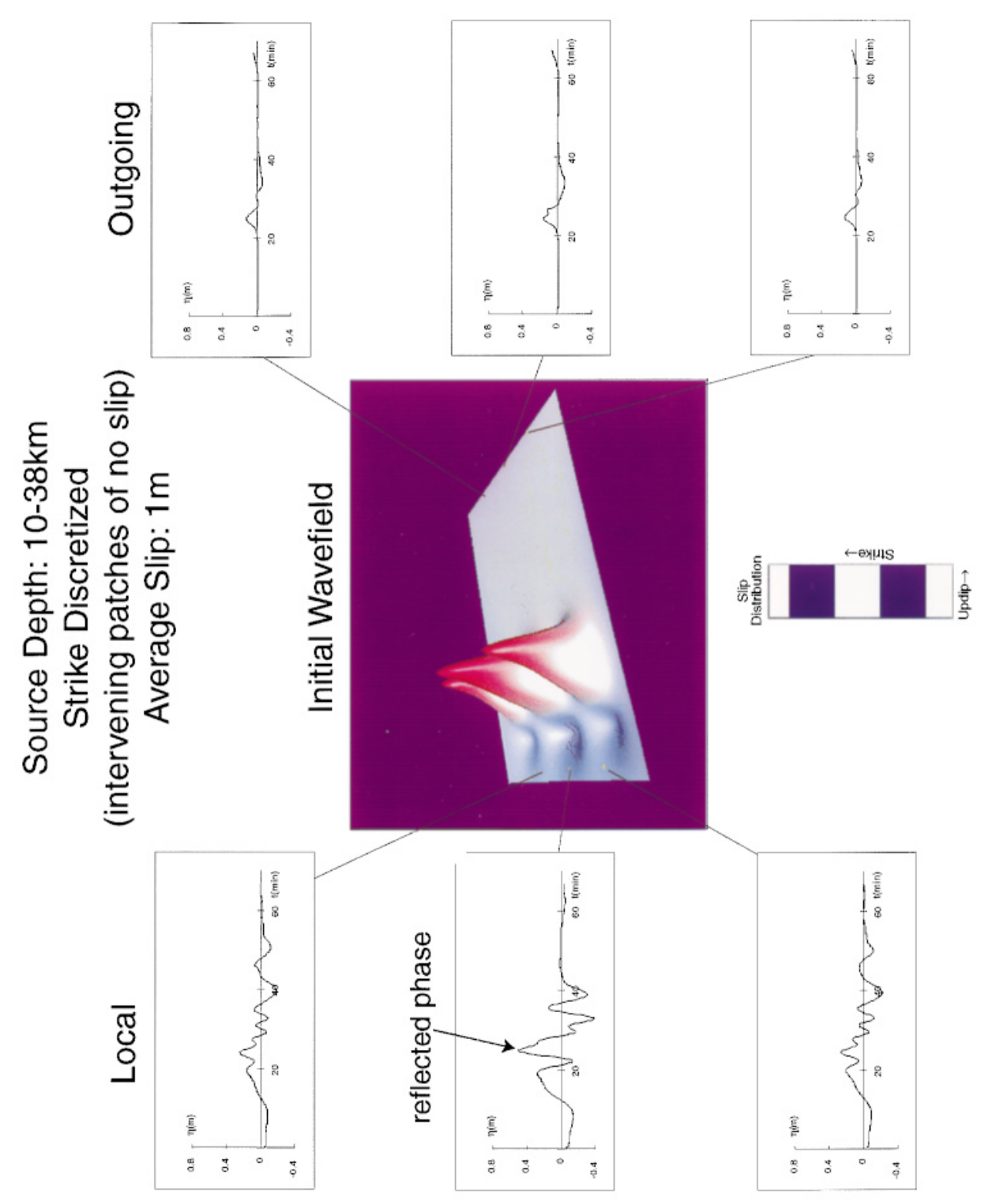


direction, but is specified as three patches of $2 \mathrm{~m}$ slip in the strike direction with intervening patches of no slip, such that the average slip over the rupture area is $1 \mathrm{~m}$ as in Figures 8 and 9. The associated wavefront-parallel changes in the amplitude of the initial tsunami wave field are largely retained for the local tsunami, owing to the effects of refraction during shoaling (GEIST, 1998). In addition, the synthetic marigram waveforms are complicated by arrivals from wave energy associated with neighboring slip patches, thus deviating from plane wave behavior displayed in Figures 8 and 9. The amplitude variations are less apparent for the outgoing tsunami, owing to the smoothing effects of geometric spreading. For both cases of non-uniform slip (Figs. 9 and 10), the maximum amplitude of the local tsunami is greater than the maximum amplitude of the tsunami associated with slip uniformly distributed over the rupture area (Fig. 8), even though the scalar seismic moment is identical for all three of the events.

\subsection{Case History: $1992 M_{w}=7.7$ Nicaragua Tsunami Earthquake}

To test the effect of different levels of discretization at the source on the local tsunami wave field, we examined the tsunami generated by the $1992 M_{w}=7.7$ Nicaragua tsunami earthquake. IHMLÉ (1996) has determined the moment density distribution for this earthquake from an inversion of seismic surface wave data. The results were discretized on a $10-\mathrm{km}$ grid size over the area of rupture $(270 \mathrm{~km}$ by $70 \mathrm{~km}$ ) and, for this study, converted to discrete slip values assuming a constant shear modulus of $\mu=3 \times 10^{10} \mathrm{~Pa}$. The left most column $(\Delta \xi=10 \mathrm{~km})$ in Figure 11 shows the slip distribution derived from IhMLÉ's (1996) result, the initial tsunami waveform (bottom), and six synthetic marigrams (top) positioned at equal increments along the right-hand side of the model domain representing the local tsunami. To remove the effects of reflections that mask the direct arrival of the local tsunami, radiation boundary conditions were used on all sides of the domain. Note the high amount of slip near the updip edge of the rupture area, possibly indicating that rupture extended to the seafloor, consistent with a surface-rupturing crack. Other model parameters are the same as used for Figures $8-10$. The other three columns to the right $(\Delta \xi=20 \mathrm{~km}, 40 \mathrm{~km}, 80 \mathrm{~km})$ represent different fault surface element sizes, in which slip was calculated as the average of the original slip distribution over 4, 16, and 64 cells, respectively. In each of the four cases, the total scalar seismic moment of the earthquake is identical. The case represented by $\Delta \xi=80 \mathrm{~km}$ is similar to the tsunami model for this earthquake presented by Piatanesi et al. (1996).

\section{Figure 10}

Initial tsunami waveform and synthetic marigrams for nonuniform slip in the strike direction. Slip is constant in the dip direction. Slip distributed in three patches of $2 \mathrm{~m}$ slip with intervening regions of no slip. Average slip for this distribution is identical to the average slip in Figures 8 and $9(1 \mathrm{~m})$. 
As the discrete surface element size representing the slip distribution is increased, the maximum amplitude of the local tsunami decreases and the dominant period increases. For the case of uniform slip in the dip direction $(\Delta \xi=80 \mathrm{~km})$, the short-wavelength component apparent in the vertical displacement field above the updip edge of rupture, rapidly dissipates during propagation. These effects are particularly apparent for the broadside marigrams (middle four marigrams of each column). Note also that using the full resolution afforded by the seismic inversion results in substantially different first arrival times for each of the marigrams. Not only do slip variations in the dip direction have a significant effect on the cross-sectional wave profile, also two-dimensional heterogeneous slip distributions result in complex local wave propagation patterns that affect later arrivals of the tsunami. For example, note the relatively large amplitude of the marigram broadside from the intervening no-slip region (fourth marigram from the top). This arrival is caused by the constructive interference of the two expanding wave fronts from the neighboring high-slip regions. As the fault surface element size increases, the amplitude of this arrival in particular is greatly diminished. The shorter wavelengths associated with higher resolution of heterogeneous slip also result in increased dispersion of the local tsunami.

\section{Discussion}

\subsection{Appropriate Resolution Limits for Local Tsunami Models}

We have shown that the local tsunami wave field is dependent on variations of slip throughout the rupture area. In particular, because the vertical displacement profile is dependent on the slip gradient, variations of slip in the dip direction must be properly accounted for to accurately model the local tsunami. As indicated by the similarity of the marigrams in Figure 11 for $\Delta \xi=10 \mathrm{~km}$ and $\Delta \xi=20 \mathrm{~km}$, small-scale variations in slip beyond the resolution of most broadband seismic waveform inversions, however, do not significantly affect the local tsunami for several reasons: (1) Variations in vertical surface displacement depend on the depth of rupture, such that the smallest wavelength in the surface displacement field is on the order of the source depth. In calculating the surface displacement field, the static elastic Green's functions essentially smooth heterogeneity at the source with increasing source depth. (2) Wavelength components of the seafloor displacement field less than approximately 3 times the water depth will be strongly attenuated with respect to the initial tsunami profile (KAJIURA, 1963). (3) Depending on the distance between the source and shoreline and the water depth at the source, geometric spreading during local propagation will also smooth short-wavelength variations of the initial tsunami wave field. For most large, interplate thrust earthquakes, the spatial resolution provided by seismic inversions is adequate to accurately reconstruct the local tsunami wave field. 

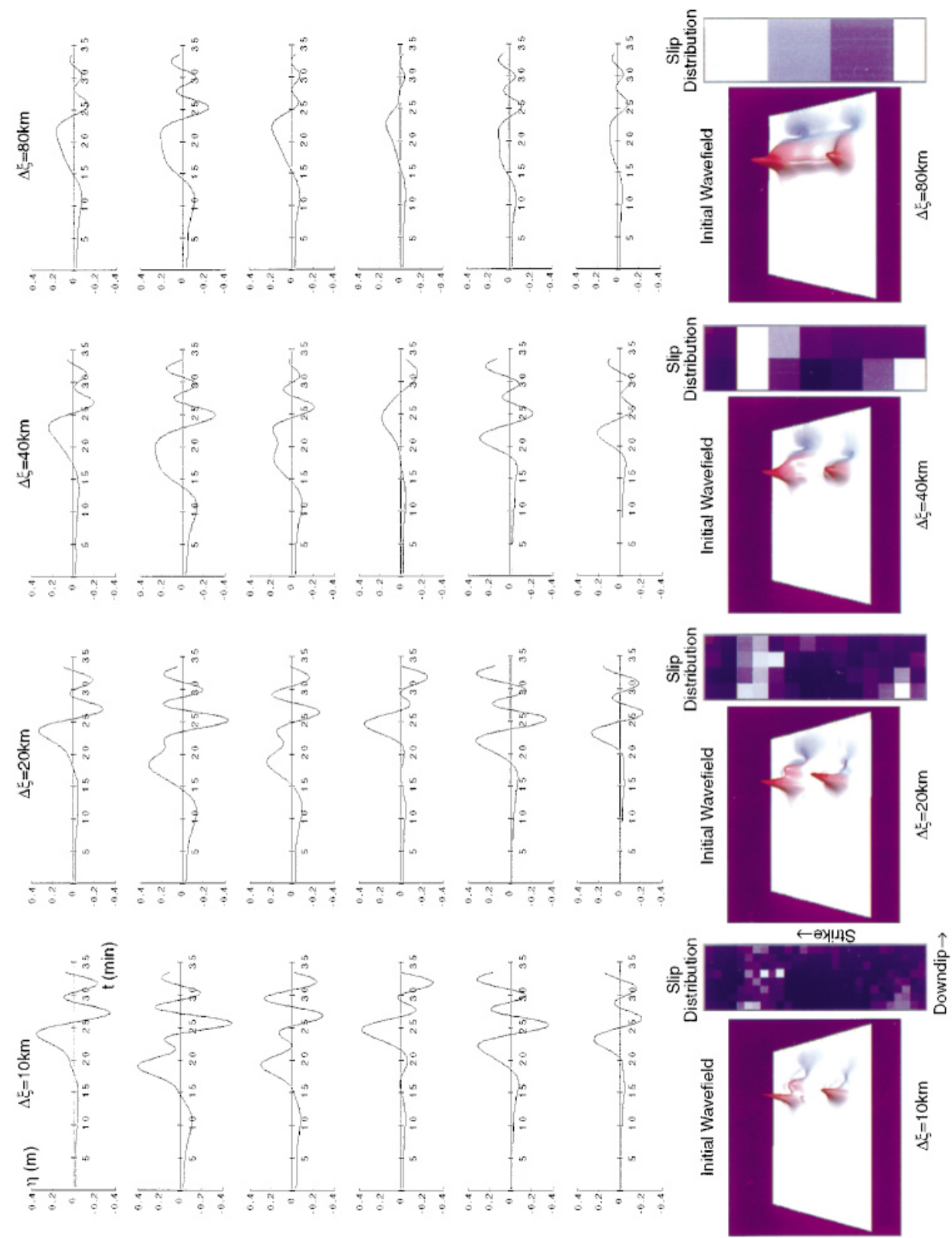


\subsection{Surface Rupture and Tsunami Earthquakes}

The perspective provided by specifying stress-drop conditions for rupture provides a framework to discuss the anomalous local runup associated with tsunami earthquakes. Tsunami earthquakes (KANAMORI, 1972) are those tsunamigenic earthquakes that generate anomalously large far-field tsunami amplitudes in relation to the surface-wave magnitude of the earthquake. Because the magnitude of the far-field tsunami can be adequately represented by the seismic moment of the earthquake (OKAL, 1988; ABE, 1995), tsunami earthquakes are also characterized by a significant $M_{s}-M_{w}$ discrepancy (PELAYO and WIENS, 1992). KANAMORI and KIKUCHI (1993) have proposed that tsunami earthquakes are often located where little sediment enters a subduction zone, such that rupture can propagate updip to the seafloor. Another observation is that the average slip associated with tsunami earthquakes is consistently higher in comparison to typical subduction zone earthquakes with the same seismic moment (GEIST, 1998). To explain this observation, previous studies as described in Section 3.1 have indicated that, for similar stress-drop conditions, the maximum and average slip increases approximately two-fold. An increase in the amount of vertical displacement associated with surface rupture depends, however, on whether the stress drop (or stress-drop distribution) is reduced because of surface rupture. At present, it is ambiguous from observations whether or not the stress drop associated with tsunami earthquakes is anomalously low (GEIST, 1998). Thus, the association of tsunami earthquakes with seafloor rupture as originally proposed by KANAMORI and KIKUCHI (1993) may also explain the anomalously high average slip values associated with these earthquakes. Other factors, however, in addition to surface rupture such as deeper water depth in the source region and shallower depth of rupture beneath the seafloor, explain the anomalously high local runup associated with these earthquakes (GEIST, 1998).

\section{Conclusions}

In this study, we have demonstrated the importance of using heterogeneous rupture models to accurately model the local tsunami wave field. In particular,

\section{Figure 11}

Effect of fault surface element size for the 1992 Nicaragua tsunami earthquake. Water depth decreases to the right. Each column represents four cases tested $(\Delta \xi=10 \mathrm{~km}, 20 \mathrm{~km}, 40 \mathrm{~km}, 80 \mathrm{~km})$. Bottom: Slip distribution within the plane of rupture (cf., Fig. 4, IHMLÉ, 1996) and perspective image of the initial tsunami wave field for each case. For both the initial wave field and slip distribution images, amplitude is normalized to the individual maximum value. Dark colors in the slip distribution represent low slip values and light colors represent high slip values. Top: Six synthetic marigrams representing the local tsunami for each case. The marigrams are equally spaced along the right side of the model domain at a water depth of $200 \mathrm{~m}$. The top and bottom marigrams of each column are oblique to the source region, whereas the middle four marigrams represent the broadside tsunami. 
tsunami models that assume that slip is uniform over the entire rupture area or over several subevents that span the entire width of rupture, underestimate both the amplitude and leading wave steepness of the local tsunami, leading to an underestimate of local tsunami runup. In addition, strike-directed slip variations are largely retained during propagation of the local tsunami, indicating that maximum runup of a local tsunami will depend on the maximum region of slip during rupture, excluding any effects caused by bathymetric variations. There are several physical mechanisms that lead to attenuation of small-scale slip variations with respect to the resulting local tsunami, such that heterogeneity of the rupture below the spatial resolution limit of modern teleseismic data does not significantly affect the local tsunami wave field. In most cases, slip distribution from seismic inversions of broadband data can therefore be used to accurately model the local tsunami wave field. Finally, the circumstance of surface rupture has a large effect on the slip distribution owing to necessarily different boundary conditions at the seafloor, possibly explaining the increased slip associated with tsunami earthquakes in comparison to typical shallow subduction zone earthquakes.

\section{Acknowledgments}

The authors are grateful for constructive reviews provided by Jingping $\mathrm{Xu}$, Rob Kayen, and two anonymous reviewers. We also thank Pierre Ihmlé for providing us with his numerical seismic inversion results of the 1992 Nicaragua earthquake.

\section{Appendix}

In contrast to the smooth displacement profile associated with crack models, the vertical displacement profile for finite dislocations along gently-dipping thrust faults exhibits short-wavelength, high-amplitude components above the updip edge of rupture (e.g., Fig. 11, $\Delta \xi=80 \mathrm{~km}$ ). The asymptotic behavior of this short-wavelength component with respect to depth $(d)$ is examined below. Vertical surface displacement for a finite, dip-slip dislocation (length $L$, width $W$ ) is given by OKADA (1985) using the geometry described therein:

where

$$
u_{z}=-\frac{U_{2}}{2 \pi}[\underbrace{\frac{\tilde{d} q}{R(R+\psi)}}+\underbrace{\sin \alpha \tan ^{-1} \frac{\psi \varphi}{q R}}-\underbrace{I_{5} \sin \alpha \cos \alpha}] \|
$$

$$
\begin{gathered}
f(\psi, \varphi) \|=f(y, p)-f(y, p-W)-f(y-L, p)+f(x-L, p-W) \\
I_{5}=\frac{\mu}{\lambda+\mu} \frac{2}{\cos \alpha} \tan ^{-1} \frac{\varphi(X+q \cos \alpha)+X(R+X) \sin \alpha}{\psi(R+X) \cos \alpha}
\end{gathered}
$$




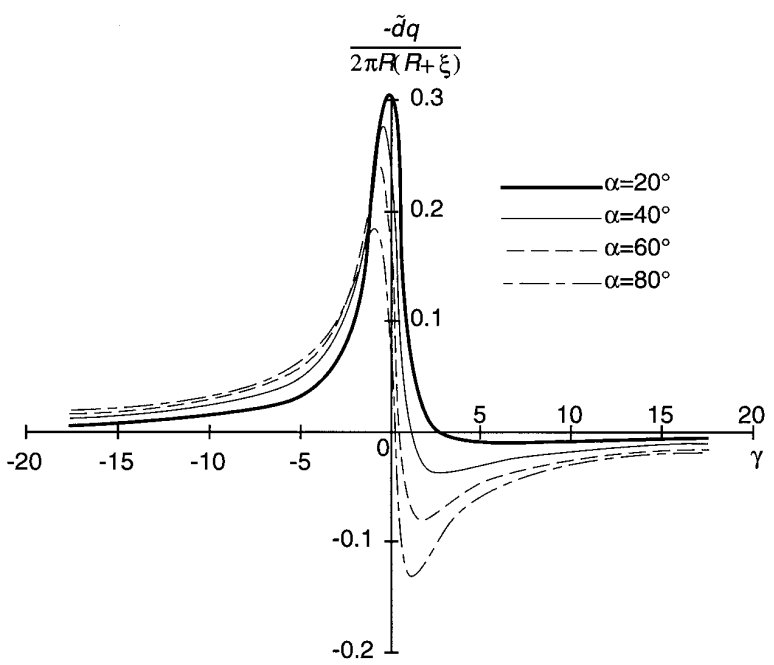

Figure A1

Quasi-invariant form (as a function of $\gamma=x-W \cos \alpha / d$ ) of the first term in the equation for vertical displacement associated with a finite dislocation (Equation (A1)). Fault dips to the left.

$$
\begin{gathered}
p=x \cos \alpha+d \sin \alpha \\
q=x \sin \alpha-d \cos \alpha \\
\tilde{d}=\varphi \sin \alpha-q \cos \alpha \\
R^{2}=\psi^{2}+\varphi^{2}+q^{2} \\
X^{2}=\psi^{2}+q^{2} .
\end{gathered}
$$

The short-wavelength component (as a function of $x$ ) arises from the first term in Equation $(\mathrm{A} 1)$ at $(\psi, \varphi)=(x-L, p-W)$. For depths less than the characteristic fault dimensions, a quasi-invariant form of this term is obtained if we examine term 1 as a function of $\gamma$ (Fig. A1) where $\gamma=x-W \cos \alpha / d$. For shallow dip angles and source depths, term 1 is characteristically larger than the other two terms in Equation (A1), whereas for steep dips, the short-wavelength component of vertical displacement above the updip edge of rupture is barely discernible, deriving from the relatively larger contributions of terms 2 and 3. As $d$ approaches $W \sin \alpha$, the horizontal scaling represented by $\gamma$ decreases such that the characteristic wavelength of this component decreases (though the amplitude remains bounded as shown in Fig. A1). For surface rupture $(d=W \sin \alpha)$, this term and $u_{z}$ are undefined at $x=W \cos \alpha$. Care must be taken therefore in choosing $d$ for finite dislocation models as input to tsunami calculations and in recognizing the existence of short-wavelength components in the vertical displacement field. 
The vertical displacement field can also be calculated for heterogeneous slip distributions by superimposing point-source solutions for the vertical displacement field given by OKADA (1985):

where

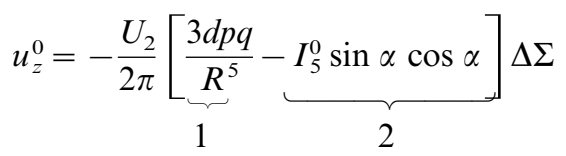

$$
\begin{gathered}
I_{5}^{0}=\frac{\mu}{\lambda+\mu}\left[\frac{1}{R(R+d)}-\left(y^{\prime}\right)^{2} \frac{2 R+d}{R^{3}(R+d)^{2}}\right] \\
p=x^{\prime} \cos \alpha+d \sin \alpha \\
q=x^{\prime} \sin \alpha-d \cos \alpha \\
R^{2}=\left(x^{\prime}\right)^{2}+\left(y^{\prime}\right)^{2}+d^{2} .
\end{gathered}
$$

$\Delta \Sigma$ is the discrete fault surface element, and the center of the surface element is positioned such that $x=y=0, z=-d$ ( $x^{\prime}$ and $y^{\prime}$ in Equation (A2) refer to this origin centered at the center of the surface element). Again, depending on the fault dip, if the depth $d$ is considerably less than the dimensions of an imbedded fault surface element, a short-wavelength component will be present in the vertical displacement field because of the asymptotic behavior of term 1 in Equation (A2).

\section{REFERENCES}

AвE, K., Estimate of tsunami run-up heights from earthquake magnitudes. In Tsunami: Progress in Prediction, Disaster Prevention and Warning (eds. Tsuchiya, N., and Shuto, Y.) (Kluwer Academic Publishers, Dordrecht 1995) pp. 21-35.

Baptista, A. M., Priest, G. R., and Murty, T. S. (1993), Field Survey of the 1992 Nicaragua Tsunami, Marine Geodesy 16, 169-203.

Ben-Zion, Y., and Rice, J. R. (1995), Slip Patterns and Earthquake Populations along Different Classes of Faults in Elastic Solids, J. Geophys. Res. 100, 12,959-12,983.

Bilby, B. A., and Eshelby, J. D., Dislocations and the theory of fracture. In Fracture, vol. I (ed. Liebowitz, H.) (Academic Press, New York 1969) pp. 99-182.

Bontwright, J., and Cocco, M. (1996), Frictional Constrains on Crustal Faulting, J. Geophys. Res. 101, 13,895-13,909.

Boore, D. M., and Dunbar, W. S. (1977), Effect of the Free Surface on Calculated Stress Drops, Bull. Seismol. Soc. Am. 67, 1661-1664.

Bürgmann, R., Pollard, D. D., and Martel, S. J. (1994), Slip Distribution on Faults: Effects of Stress Gradients, Inelastic Deformation, Heterogeneous Host-rock Stiffness, and Fault Interaction, J. Struct. Geol. 16, 1675-1690.

Cochard, A., and Madariaga, R. (1996), Complexity of Seismicity due to Highly Rate-dependent Friction, J. Geophys. Res. 101, 25,321-25,336.

Cowie, P. A., and SCHOlz, C. H. (1992), Physical Explanation for the Displacement-length Relationship of Faults Using a Post-yield Fracture Mechanics Model, J. Struct. Geol. 14, 1133-1148.

Cowie, P. A., and Shipton, Z. K. (1998), Fault Tip Displacement Gradients and Process Zone Dimensions, J. Struct. Geol. 20, 983-997. 
DAs, S. (1981), Three-dimensional Rupture Propagation and Implications for the Earthquake Source Mechanism, Geophys. J. R. Astron. Soc. 67, 375-393.

DAs, S., and AKI, K. (1977), Fault Plane with Barriers: A Versatile Earthquake Model, J. Geophys. Res. $82,5648-5670$.

Das, S., and Suhadolc, P. (1996), On the Inverse Problem for Earthquake Rupture: The Haskell-type Source Model, J. Geophys. Res. 101, 5725-5738.

Dieterich, J. H. (1979), Modeling of Rock Friction, 1, Experimental Results and Constitutive Equations, J. Geophys. Res. 84, 2161-2168.

DmowskA, R., and Kostrov, B. V. (1973), A Shearing Crack in a Semi-space under Plane Strain Conditions, Archives of Mechanics 25, 421-440.

DMowskA, R., and Rice, J. R., Fracture theory and its seismological applications. In Continuum Theories in Solid Earth Physics (ed. Teisseyre, R.) (PWN-Polish Scientific Publishers, Warsaw 1986) pp. $187-255$.

Erdogan, F., and Gupta, G. D. (1972), On the Numerical Solution of Singular Integral Equations, Quart. J. Mech. Appl. Math. 29, 4-9.

Freund, L. B., and Barnett, D. M. (1976), A Two-dimensional Analysis of Surface Deformation due to Dip-slip Faulting, Bull. Seismol. Soc. Am. 66, 667-675.

Fukuyama, E., and Madariaga, R. (1995), Integral Equation Method for Plane Crack with Arbitrary Shape in 3-D Elastic Medium, Bull. Seismol. Soc. Am. 85, 614-628.

GEIST, E. L. (1998), Local tsunamis and earthquake source parameters. In Tsunamigenic Earthquakes and their Consequences (eds. Dmowska, R., and Saltzman, B) Advances in Geophysics 39, 117-209.

IDA, Y. (1973), Stress Concentration and Unsteady Propagation of Longitudinal Shear Cracks, J. Geophys. Res. 78, 3418-3429.

Ihmlé, P. F. (1996), Monte Carlo Slip Conversion in the Frequency Domain: Application to the 1992 Nicaragua Slow Earthquake, Geophys. Res. Lett. 23, 913-916.

Jeyakumaran, M., Rudnicki, J. W., and Keer, L. M. (1992), Modeling Slip Zones with Triangular Dislocation Elements, Bull. Seismol. Soc. Am. 82, 2153-2169.

KAJiUrA, K. (1963), The Leading Wave of a Tsunami, Bull. Earthquake Res. Inst. 41, 535-571.

Kajiura, K. (1981), Tsunami Energy in Relation to Parameters of the Earthquake Fault Model, Bull. Earthquake Res. Inst. 56, 415-440.

KANAmori, H. (1972), Mechanism of Tsunami Earthquakes, Phys. Earth Planet. Interiors 6, 346-359.

Kanamori, H., and KIKUCHI, M. (1993), The 1992 Nicaragua Earthquake: A Slow Tsunami Earthquake Associated with Subducted Sediments, Nature 361, 714-716.

KNOPOFF, L. (1958), Energy Release in Earthquakes, Geophys. J. 1, 44-52.

Kostrov, B. V., and Das, S. (1984), Evaluation of Stress and Displacement Fields due to an Elliptical Plane Shear Crack, Geophys. J. Royal Astr. Soc. 77, 915-933.

MA, X. Q., and Kusznir, N. J. (1992), 3-D Subsurface Displacement and Strain Fields for Faults and Fault Arrays in a Layered Elastic Half-space, Geophys. J. Int. 111, 542-558.

McTigue, D. F., and Segall, P. (1988), Displacements and Tilts from Dip-slip Faults and Magma Chambers beneath Irregular Surface Topography, Geophys. Res. Lett. 16, 601-604.

OkAdA, Y. (1985), Surface Deformation due to Shear and Tensile Faults in a Half-space, Bull. Seismol. Soc. Am. 75, 1135-1154.

OKal, E. A. (1988), Seismic Parameters Controlling Far-field Tsunami Amplitudes: A Review, Natural Hazards 1, 67-96.

Pelayo, A. M., and Wiens, D. A. (1992), Tsunami Earthquakes: Slow Thrust-faulting Events in the Accretionary Wedge, J. Geophys. Res. 97, 15,321-15,337.

Piatanesi, A., Tinti, S., and Gavagni, I. (1996), The Slip Distribution of the 1992 Nicaragua Earthquake from Tsunami Run-up Data, Geophys. Res. Lett. 23, 37-40.

Reid, R. O., and Bodine, B. R. (1968), Numerical Model for Storm Surges in Galveston Bay, J. Waterway Harbor Div. 94, 33-57.

RICE, J. R., Mathematical analysis in the mechanics of fracture. In Fracture, vol. II (ed. H. Liebowitz) (Academic Press, New York 1968) pp. 191-311.

Rudnicki, J. W., and Wu, M. (1995), Mechanics of Dip-slip Faulting in an Elastic Half-space, J. Geophys. Res. 100, 22,173-22,186. 
Rybicki, K., Dislocations and their geophysical application. In Continuum Theories in Solid Earth Physics (ed. Teisseyre, R.) (PWN-Polish Scientific Publishers, Warsaw 1986) pp. 18-186.

Satake, K. (1993), Depth Distribution of Coseismic Slip along the Nankai Trough, Japan, from Joint Inversion of Geodetic and Tsunami Data, J. Geophys. Res. 98, 4553-4565.

Savage, J. C. (1998), Displacement Field for an Edge Dislocation in a Layered Half-space, J. Geophys. Res. 103, 2439-2446.

Savage, J. C., and Hastie, L. M. (1966), Surface Deformation Associated with Dip-slip Faulting, J. Geophys. Res. 71, 4897-4904.

SHIMAZAKI, K., Small and large earthquakes: The effects of the thickness of seismogenic layer and the free surface. In Earthquake Source Mechanics (eds., Das, S., Boatwright, J., and Scholz, C.) (American Geophysical Union, Washington, D.C. 1986) pp. 209-216.

Singh, S. J., Punia, M., and Rani, S. (1994), Crustal Deformation due to Non-uniform Slip along a Long Fault, Geophys. J. Int. 118, 411-427.

StuArT, W. D. (1988), Forecast Model for Great Earthquakes at the Nankai Trough Subduction Zone, Pure appl. geophys. 126, 619-641.

Stoker, J. J., Water Waves (Interscience Publishers Inc., New York 1957) 567 pp.

SynOlakis, C. E. (1987), The Runup of Solitary Waves, J. Fluid Mech. 185, 523-545.

TADA, T., and Yamashita, T. (1997), Non-hypersingular Boundary Integral Equations for Two-dimensional Non-planar Crack Analysis, Geophys. J. Int. 130, 269-282.

Tadepalli, S., and Synolakis, C. E. (1994), The Run-up of $N$ Waves on Sloping Beaches, Proc. R. Soc. Lond. A 445, 99-112.

Tadepalli, S., and Synolakis, C. E. (1996), Model for the Leading Waves of Tsunamis, Phys. Rev. Lett. 77, 2141-2144.

Tanioka, Y., and Satake, K. (1996), Tsunami Generation by Horizontal Displacement of Ocean Bottom, Geophys. Res. Lett. 23, 861-864.

Thatcher, W. (1990), Order and Diversity in the Modes of Circum-Pacific Earthquake Recurrence, J. Geophys. Res. 95, 2609-2623.

ToGASHI, H., Shoreline wave height and land run-up height of tsunamis on uniformly sloping beaches. In Tsunamis: Their Science and Engineering (eds. Iida, J., and Iwasaki, T.) (Terra Science Pub. Co., Tokyo/Reidel, Dordrecht 1983) pp. 495-509.

TSE, S. T., and Rice, J. R. (1986), Crustal Earthquake Instability in Relation to the Depth Variation of Frictional Slip Properties, J. Geophys. Res. 91, 9452-9472.

Tsuji, Y., Imamura, F., Matsutomi, H., Synolakis, C. E., Nanang, P. T., Jumadi, S., Harada, S., Han, S. S., ARAI, K., and CoOK, B. (1995), Field Survey of the East Java Earthquake and Tsunami of June 3, 1994, Pure appl. geophys. 144, 839-854.

Weertman, J. (1964), Continuum Distribution of Dislocations on Faults with Finite Friction, Bull. Seismol. Soc. Am. 54, 1035-1058.

Wu, M., Rudnicki, J. W., Kuo, C. H., and Keer, L. M. (1991), Surface Deformation and Energy Release Rates for Constant Stress Drop Slip Zones in an Elastic Half-space, J. Geophys. Res. 96, $16,509-16,524$.

(Received April 17, 1998, revised/accepted December 15, 1998) 